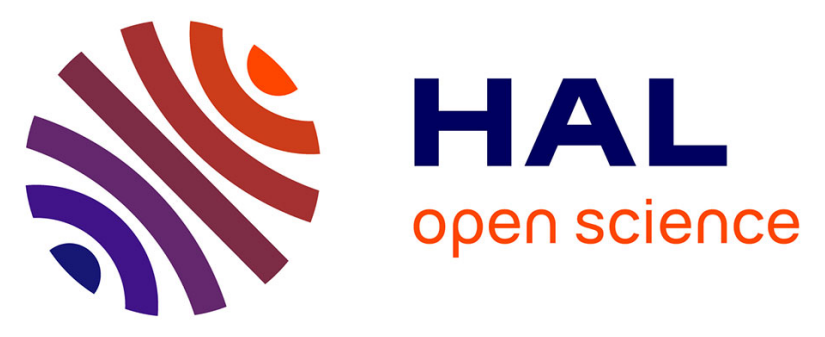

\title{
Meniscus sutures by arthrotomy for a non-transfixing horizontal lesion associated with a cyst
}

Nicolas Girodano Orsini, Henri Favreau, David Eichler, Matthieu Ollivier, François Bonnomet, Matthieu Ehlinger

\section{- To cite this version:}

Nicolas Girodano Orsini, Henri Favreau, David Eichler, Matthieu Ollivier, François Bonnomet, et al. Meniscus sutures by arthrotomy for a non-transfixing horizontal lesion associated with a cyst. International Orthopaedics, 2020, 44 (6), pp.1071-1076. 10.1007/s00264-020-04491-3 . hal-03176967

\section{HAL Id: hal-03176967 \\ https://hal.science/hal-03176967}

Submitted on 15 Apr 2021

HAL is a multi-disciplinary open access archive for the deposit and dissemination of scientific research documents, whether they are published or not. The documents may come from teaching and research institutions in France or abroad, or from public or private research centers.
L'archive ouverte pluridisciplinaire HAL, est destinée au dépôt et à la diffusion de documents scientifiques de niveau recherche, publiés ou non, émanant des établissements d'enseignement et de recherche français ou étrangers, des laboratoires publics ou privés. 


\title{
Meniscus sutures by arthrotomy for a non-transfixing horizontal lesion associated with a cyst
}

\author{
Nicolas Girodano Orsini ${ }^{1}$ - Henri Favreau ${ }^{1}$ - David Eichler ${ }^{1}$ - Matthieu Ollivier ${ }^{2}$ - François Bonnomet ${ }^{1}$. \\ Matthieu Ehlinger ${ }^{1,3}$ (iD
}

\begin{abstract}
Introduction Meniscal cysts are rare in Stoller grade II horizontal lesions. Several techniques are described in the literature for their management, without any real gold standard. The objective of this work was to report a series of meniscal sutures associated with cyst resection by arthrotomy. The hypothesis was that the results were satisfactory and comparable with the data in the literature regardless of the technique reported without morbidity added by arthrotomy.

Materials and methods This was a monocentric retrospective study on 13 patients, aged 33 on average with a grade II meniscus lesion associated with a cyst (9 lateral and 4 medial menisci). Pre-operative data available was the VAS (5.7/10) and the Lysholm score (61/100). Primary endpoints were as follows: pain (visual analogue scale), global satisfaction, Lysholm functional score, and return to sports and professional activities at a minimum of two years. Secondary endpoints were complications, possible recurrence, and/or surgical revision. Recurrences, complications, and surgical recovery were gathered.

Results Patients were evaluated with an average follow-up of 32 months. All patients were satisfied or very satisfied. The VAS significantly improved $(0.2 / 10, p<0.05)$ as well as the Lysholm score $(97 / 100, p<0.05)$. All patients returned to their professional activity: 11 within two months, one within six weeks, and one in the first post-operative week (this patient being a student). Only one patient did not resume pre-operative sport level due to a femoropatellar syndrome, not linked to the meniscal surgery performed. However, only 11 patients resumed their previous sport level (84.6\%). No recurrence or surgical revision occurred. Discussion The results are good and similar to the literature, confirming the working hypothesis. These results are equivalent to partial meniscectomies and arthroscopic sutures associated with a procedure on the cyst by arthroscopy or arthrotomy. The literature is in favour of a procedure on the cyst.

Conclusion The results confirm the effectiveness of a direct approach suture of non-transfixing meniscal lesions associated with a cyst resection with a good functional recovery, without additional morbidity. The hypothesis was confirmed.
\end{abstract}

Keywords Knee $\cdot$ Meniscus $\cdot$ Meniscal tear $\cdot$ Arthrotomy $\cdot$ Meniscal cyst

Level of evidence: IV, retrospective study

Matthieu Ehlinger

Matthieu.ehlinger@chru-strasbourg.fr

1 Service de Chirurgie Orthopédique et de Traumatologie, Hôpital de Hautepierre, Hôpitaux Universitaires de Strasbourg, 1 avenue Molière, 67098 Strasbourg cedex, France

2 Département de Chirurgie Orthopédique, Hôpital Sainte-Marguerite, Hôpital Universitaire de Marseille, 270 boulevard Sainte Marguerite, 13009 Marseille, France

3 Laboratoire ICube, équipe MMB, CNRS, Illkirch, France

\section{Introduction}

Horizontal meniscal cleavage associated with a cyst is seldom (less than $8 \%$ when a meniscal lesion is present) [1]. The cleavage into two layers leads to a myxoid degeneration of the meniscal tissue which can rupture through the peripheral margin producing the associated cyst [2]. These lesions, classified by Stoller [3], can be transfixing with a communication with the free edge of the meniscus: stage 1: one or several punctate or nodular hypersignal not contiguous with an articular surface, stage 2: linear hypersignal without articular surface extension, stage 3: linear or complex hypersignal extended to at least one articular surface. 
For stage I and II lesions, which are usually asymptomatic, simple monitoring is proposed. However, when associated with a cyst, they can become symptomatic and painful. If proper medical treatment does not improve symptomatology, intra-articular injection of corticosteroids or puncture/ evacuation of the cyst associated with intracystic injection of corticosteroids may be proposed. Surgical treatment is proposed after persisting medical management failure. Meniscal suture is preferred $[4,5]$, as there is risk of osteoarthritis induced by meniscectomy, even partial $[6,7]$. Grade II meniscus lesions do not extend to the surface, making arthroscopy almost unnecessary. In addition, the meniscus lesion and cyst are located in the vascular zone with a high healing potential.

In this work, a direct approach by arthrotomy was made to address these types II lesions associated with a cyst, which facilitates abrasion and quality of meniscal repair while allowing complete resection of the cyst.

The main objective was to report the results of these meniscal sutures by arthrotomy with cyst resection at minimum two year follow-up by evaluating the pain reported by the patient (visual analogue scale (VAS)), the functional evaluation according to the Lysholm score [8], and return to professional and sporting activities. The secondary objective was to analyze possible complications, recurrences, and surgical revisions. The hypothesis was that the results were good and comparable with the data in the literature.

\section{Material and method}

\section{Type of study and inclusion criteria}

This was a retrospective, monocentric study from July 2015 to May 2017 with a minimum two years follow-up; hence, the majority of surgical revisions for suture failure occurred within the first 24 months [9].

All patients were operated on by the same surgeon.

Each patient had a pre-operative knee examination, standard radiographs, and a knee MRI.

The inclusion criteria were:

- A symptomatic meniscal lesion with a palpable cyst

- A failure of medical treatment properly conducted over three months

- A stable knee

- A meniscal horizontal cleavage grade I or II [3]

The exclusion criteria were:

- A rupture of the ACL (operated or not)

- A history of knee surgery

- A grade III meniscal lesion [3]

\section{Evaluation}

The main evaluation criteria were:

- pain (VAS)

- global satisfaction (very satisfied, satisfied, disappointed)

- Lysholm score [8] (pre-operative and post-operative)

- $\quad$ return to professional and sporting activities (delay and level)

The secondary criteria were presence of:

- a complication

- a recurrence

- a surgical revision

In addition, we reported the following: age, sex, body mass index (BMI), duration of symptoms before surgery (months), laterality and segment of the meniscus concerned, the cyst's largest diameter, single or polylobed shape, position of the cyst in relation to the collateral ligament (medial or lateral), the presence of a cartilage lesion (MRI classification derived from the ICRS arthroscopic one) [10], the axis of the lower limb (hip-knee-ankle (HKA) angle), tourniquet time, the approach used (pre or retro-ligament approach), return to professional activity delay and level, return to sport delay and level (similar or different from the one prior to surgery).

\section{The series (Table 1)}

We analyzed 13 patients ( 4 women and 9 men), of average age 33 (18-56), with 9 lateral and 4 medial menisci and average BMI $26 \mathrm{~kg} / \mathrm{m}^{2}$ (21-32). A history of trauma was present only in ten cases. The average duration of symptoms prior to surgery was 14 months (3-36). The pre-operative VAS was 5.7/ 10 (4-7) and the Lysholm score [8] was 61/100.

Eleven patients had a HKA angle of less than $180^{\circ}\left( \pm 3^{\circ}\right)$, and one had a bilateral varus of $6^{\circ}$, without evidence of osteoarthritis.

All patients had a grade II lesion [3]; there was no radial meniscal tear. A grade III meniscal lesion of the opposite compartment was present in one patient and was sutured by arthroscopy. Concerning the lateral meniscus, the anterior segment was affected alone three times, the anterior and middle segments together twice, the middle and posterior segments twice, and the three segments twice. For the medial meniscus, there was one anterior and middle segment lesion, one lesion of the middle and posterior segments, and two isolated posterior lesions. Lateral cysts were ante-ligamentous eight times and retro-ligamentous once. Medial cysts were three times retro-ligamentous and ante-ligamentous once. Five cysts were single-lobed and eight polylobed. The average cyst size was $20 \mathrm{~mm}$ (14-33). On MRI, cartilage was healthy for ten patients. There was one grade I lesion and two grade II lesions. 
Table 1 Preoperative characteristics of the series

\begin{tabular}{|c|c|c|c|c|c|c|c|c|c|c|c|c|}
\hline $\begin{array}{l}\text { Case } \\
\text { number }\end{array}$ & Sex & $\begin{array}{l}\text { Age } \\
\text { (years) }\end{array}$ & BMI & $\begin{array}{l}\text { Duration of } \\
\text { symptoms } \\
\text { (months) }\end{array}$ & $\begin{array}{l}\text { Laterality } \\
\text { of lesion }\end{array}$ & Grade [3] & $\begin{array}{l}\text { Size } \\
\text { of cyst } \\
(\mathrm{mm})\end{array}$ & $\begin{array}{l}\text { Single or } \\
\text { polylobed }\end{array}$ & Segment concerned & $\begin{array}{l}\text { Pre- or } \\
\text { retro-ligament } \\
\text { position }\end{array}$ & $\begin{array}{l}\text { VAS } \\
\text { on } 10\end{array}$ & $\begin{array}{l}\text { Lysholm } \\
\text { on } 100 \text { [8] }\end{array}$ \\
\hline 1 & $\mathrm{H}$ & 21 & 30 & 6 & Lateral & II & 18 & Poly & Anterior & Pre & 7 & 60 \\
\hline 2 & $\mathrm{H}$ & 19 & 22 & 9 & Lateral & II & 14 & Poly & Anterior and middle & Pre & 5 & 65 \\
\hline 3 & $\mathrm{H}$ & 56 & 32 & 12 & Medial & II & 16 & Single & Anterior and middle & Pre & 5 & 59 \\
\hline 4 & $\mathrm{H}$ & 18 & 22 & 36 & Lateral & II & 18 & Poly & Anterior and middle & Pre & 6 & 64 \\
\hline 5 & $\mathrm{~F}$ & 29 & 32 & 21 & Lateral & II & 25 & Poly & Middle and posterior & Retro & 5 & 60 \\
\hline 6 & $\mathrm{H}$ & 46 & 28 & 3 & Medial & IIs & 18 & Poly & posterior & Retro & 8 & 58 \\
\hline 7 & $\mathrm{~F}$ & 30 & 20 & 12 & Medial & II & 29 & Single & posterior & Retro & 6 & 57 \\
\hline 8 & $\mathrm{H}$ & 26 & 28 & 24 & Lateral & II & 20 & Single & Anterior & Pre & 5 & 63 \\
\hline 9 & $\mathrm{H}$ & 33 & 22 & 9 & Lateral & II & 21 & Poly & Middle and posterior & Pre & 4 & 56 \\
\hline 10 & $\mathrm{H}$ & 33 & 21 & 6 & Medial & II & 18 & Poly & Middle and posterior & Retro & 4 & 65 \\
\hline 11 & $\mathrm{~F}$ & 39 & 28 & 25 & Lateral & II & 15 & Single & $\begin{array}{l}\text { Anterior, middle and } \\
\text { posterior }\end{array}$ & Pre & 6 & 62 \\
\hline 12 & $\mathrm{H}$ & 42 & 32 & 15 & Lateral & II & 33 & Poly & $\begin{array}{l}\text { Anterior, middle and } \\
\text { posterior }\end{array}$ & Pre & 7 & 58 \\
\hline 13 & $\mathrm{~F}$ & 21 & 26 & 9 & Lateral & II & 20 & Single & Anterior & Pre & 6 & 60 \\
\hline
\end{tabular}

H: male

F: female

\section{Surgical technique}

The patient was placed in supine position with one knee bent at $80^{\circ}$. A $300-\mathrm{mmHg}$ tourniquet was inflated with an average duration of 32 minutes (20-50 for the patient who had an associated arthroscopy).

The meniscal cyst was palpated and either a pre- or retroligament approach was performed, depending on the position of the cyst. The skin was incised. The collateral ligament was identified. The cyst was approached directly and isolated for a monoblock excision. Histopathology analysis of the cyst was systematically made. Then, the operation continued with arthrotomy which is performed through the surgical approach used to resect the cyst (Fig. 1). The arthrotomy was performed with a vertical incision centered on the joint space, allowing a better stress distribution on the capsule sutures at closure. The meniscal horizontal tear was found and abrased out-in with a curette and then sutured by separate vertical points using a 3/0 vicryl thread, taking care to attach the meniscus to its "wall." The stitches were always made from back to front with an average space of 3 to $5 \mathrm{~mm}$. The knee was extended to check the holding of the suture and full extension. After that, the different surgical planes were sutured too.

Arthrotomy where the cyst was removed (so in front of the meniscal tear) is for us the better option to treat the lesion. As the articular surface of the meniscus is healthy, the only solution is to approach it directly, by an outside way. In this case, arthroscopy is not useful.

Immediate full weight bearing was allowed with flexion limited at $90^{\circ}$ for the first four weeks, then free range of motion.
Return to non-pivoting sports was allowed in the third postoperative month and pivoting sports six months after surgery.

\section{Statistical analysis}

The statistical analysis was descriptive. The quantitative data (clinical scores, VAS) were compared according to Student's $t$ test with a significance threshold set at $p<0.05$ (SAS software).
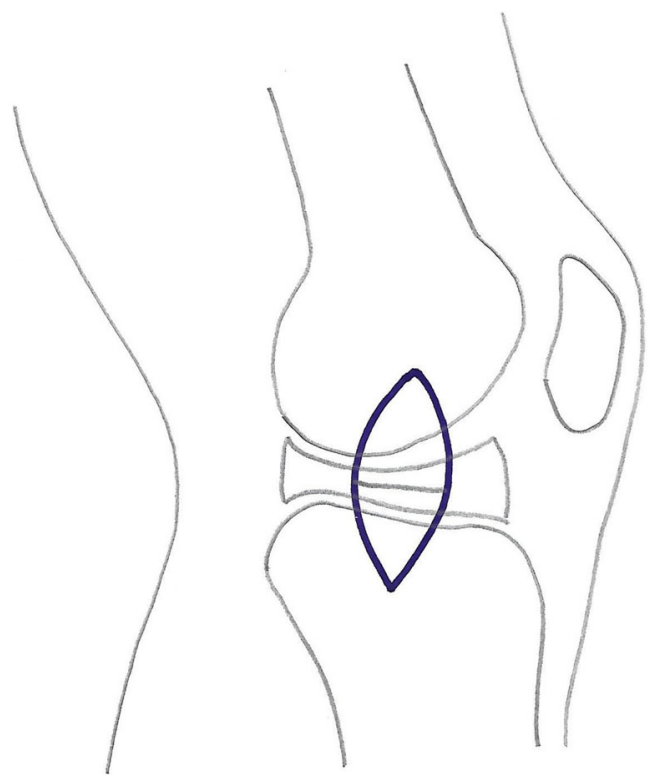

Fig. 1 The surgical approach and access to suture and treat the meniscal tear 


\section{Results}

All patients were reviewed. The average follow-up was 32 months (24-47) (Table 2).

The main criteria are as follows:

- All patients were satisfied or very satisfied.

- The average VAS was $0.2 / 10(p<0.05$ compared with pre-operative data). Only one patient had 3/10 VAS with pain in the anterior compartment of the knee related to a patellofemoral syndrome that occurred 2 years after surgery. Additional imaging did not show any recurrence of injury.

- $\quad$ The mean Lysholm score [8] was 97 (91-100) $(p<0.05$ compared with the pre-operative data).

- Return to previous professional activity was effective at 6 weeks for one case and at eight weeks for 11 patients. One patient was a student.

- Return to non-pivotal sports was authorized in the third month for 12 patients and in the fifth month for one patient with mild persistent pain at the third month postoperative clinical visit. Return to pivotal sports began as planned after 6 months for 11 patients and eight months for the two patients. All patients resumed the same sport except for the patient with a femoropatellar syndrome, but only 11 patients resumed their sport at the same level.

The secondary criteria are the following:

- No immediate or late post-operative complications were observed.

- There was no recurrence of cyst or meniscal lesion.

- No secondary surgical procedure was performed.

There was no correlation with the different characteristics of the cyst, the meniscal segment concerned, the approach used, the laterality of the lesion, or the presence of a cartilage lesion.

\section{Discussion}

The results of this series are good, comparable with the data in the literature, confirming the working hypothesis. Patient satisfaction was complete with a mean VAS of $0.2 / 10$ and a significant improvement $(p<0.05)$. Only one knee remained painful but unrelated to the initial injury. Functional results were also satisfactory with a significantly improved Lysholm score [8] $(97 / 100, p<0.05)$. No approach-related morbidity was found, nor was there any recurrence. Finally, return to professional and sporting activities was possible with almost no restrictions.
There are limitations to this work. These uncommon lesions limited the number of patients available for this retrospective study. The average follow-up is relatively short but remains adequate as most suture failures occur in the first two years [9]. Finally, no systematic radiological examination was performed to obtain precise evidence of the absence of recurrence, but the post-operative clinical presentation did not justify complementary imaging. On the other hand, it also has strengths because it is a continuous, homogeneous series with an identical surgical technique performed by one operator.

These results are comparable with those in the literature regardless of the surgical technique used. Indeed, there is no consensus on management: arthroscopic meniscal surgery or direct approach, procedure on the cyst or not. Some authors propose an arthroscopic meniscal regularization associated with an extra-articular procedure on the cyst with very good results [11-21]. A procedure on the cyst is recommended.

Hulet et al. [11] reported excellent or good results in $87 \%$ of their 105 patients operated on for partial meniscectomy with arthroscopic debridement of the cyst or direct approach resection. Bombaci et al. [12] proposed partial arthroscopic meniscectomy isolated or associated with extra-articular drainage of the cyst. They reported eight cases of meniscal lesions (7 lateral and 1 medial). Results were improved for VAS: 6/10 (2-8) preoperative and 1.55/10 (0-3) post-operative and for the Lysholm score [8] (pre- and post-operative respectively $64.75(48-86)$ and $93.11(80-100))$ without difference between the two options. Dai et al. [13] studied 33 patients with lateral cystic lesion treated by excision associated with meniscal suture, all under arthroscopy. The results at 7.5 months of decline were excellent or good in all cases, with a Lysholm score [8] going from 61/100 to 91/100. They had no recurrence of cyst or meniscal lesion, but the follow-up was short. Chen et al. [14] had similar results on 64 patients at 28 months follow-up for full arthroscopic management. Reagan et al. [15] also found excellent results in $80 \%$ of cases but for arthroscopic partial meniscectomy with or without extra-articular drainage of the cyst. They recommended to perform a procedure on the cyst because they obtained only $50 \%$ excellent results when the drainage was not done. Glasgow et al. [16] performed arthroscopic meniscectomy and arthroscopic decompression on 72cystic lateral menisci. They obtained a good or excellent result for $89 \%$ of patients at 34 months follow-up. This was confirmed by Calvisi et al. [17].

On the other hand, other authors, such as Kumar et al. [18], never associated any procedure on the cyst. Nevertheless, the results were also very good with a Lysholm score at 89.1 at five years follow-up in fourteen patients (eight lateral and six medial cysts). Contrary to what Reagan et al. [15] reported.

Sarimo et al. [19] compared a suture associated with an open procedure on the cyst to an arthroscopic treatment. This series included 35 cases with an average follow-up of 33 months. Short-term results were good in $86 \%$ of cases, with no significant difference between the two surgical treatments. 
Table 2 Results at follow-up (FU)

\begin{tabular}{|c|c|c|c|c|c|c|c|c|c|}
\hline $\begin{array}{l}\text { Case } \\
\text { number }\end{array}$ & $\begin{array}{l}\text { FU } \\
\text { (months) }\end{array}$ & Satisfaction & VAS & $\begin{array}{l}\text { Range of } \\
\text { motion }\left(^{\circ}\right)\end{array}$ & Lysholm [8] & Professional activity & Sport level & $\begin{array}{l}\text { Return to sport } \\
\text { delay (weeks) }\end{array}$ & $\begin{array}{l}\text { Return to professional } \\
\text { activity delay (weeks) }\end{array}$ \\
\hline 1 & 47 & Good & 0 & $0-130$ & 91 & Similar & Similar & 6 & 8 \\
\hline 2 & 44 & Very good & 0 & $0-140$ & 95 & Similar & Similar & 6 & 6 \\
\hline 3 & 37 & Very good & 0 & $0-130$ & 99 & Similar & Similar & 6 & 8 \\
\hline 4 & 36 & Very good & 0 & $0-140$ & 100 & Similar & Similar & 6 & 1 \\
\hline 5 & 36 & Very good & 0 & $0-140$ & 100 & Similar & Similar & 6 & 8 \\
\hline 6 & 33 & Very good & 0 & $0-130$ & 94 & Similar & Similar & 6 & 8 \\
\hline 7 & 29 & Good & 3 & $0-120$ & 91 & Similar & No return to sport & 8 & 8 \\
\hline 8 & 27 & Very good & 0 & $0-130$ & 99 & Similar & Similar & 6 & 8 \\
\hline 9 & 26 & Very good & 0 & $0-140$ & 99 & Similar & Similar & 6 & 8 \\
\hline 10 & 25 & Very good & 0 & $0-140$ & 100 & Similar & Different & 6 & 8 \\
\hline 11 & 25 & Very good & 0 & $0-130$ & 99 & Similar & Similar & 8 & 8 \\
\hline 12 & 24 & Very good & 0 & $0-130$ & 100 & Similar & Similar & 6 & 8 \\
\hline 13 & 24 & Very good & 0 & $0-140$ & 99 & Similar & Similar & 6 & 8 \\
\hline
\end{tabular}

Finally, regarding grade I or II meniscal repair without cystic lesion, Beaufils et al. [20] recommended arthrotomy repair in these horizontal lesions for two main reasons: debridement by intra-articular approach cannot be achieved without damaging the meniscus and vertical suture through the two meniscal sheets seems more robust than oblique suture by arthroscopy.

Regarding secondary evaluation criteria, in particular return to sport, Hulet et al. [11] observed a return to sport at the same level in $77 \%$ of cases. Pujol et al. [21] reported a better rate of sport recovery at a similar level (95\%) as did Dai et al. [13].

No complication or recurrence nor secondary procedure was noted in this work, emphasizing the safety of a direct approach to the cyst and meniscus lesion. The literature supports this view with Dai et al. [13] who did not observe any complication, but with a short follow-up of 7.5 months. The same is true for Glasgow et al. [16] and Chen et al. [14]. On the other hand, Pujol et al. [21], on a retrospective series of 21 patients (80\% meniscal sutures, $20 \%$ partial meniscectomy) for horizontal grade II lesions (11 cases) and III (10 cases) most often associated with a cyst (15 cases), did not observe any recurrence of cyst, but four secondary meniscectomies were necessary $(20 \%)$. These results are confirmed by the literature for vertical lesions $[5,22,23]$ and in particular by two meta-analyses $[24,25]$ which found secondary meniscectomy rates of $15 \%$ and $23 \%$ respectively. The 2003 SFA symposium reported a failure rate of $23 \%$ at 4 years [26]. Bombaci et al. [12] had symptomatic and asymptomatic recurrence of the cyst. Hulet et al. [11] reported a series of 105 patients with cystic recurrence observed in eleven cases $(10.5 \%)$. All cases were purely arthroscopic (meniscus and cyst). This suggests that there is insufficient treatment of lesions that may be related to poor arthroscopic exposure.
In summary, we propose the following algorithm. For Stoller lesions [3] 1 and 2 associated with a cyst, the surgical management proposed here seems to be the most suitable. For Stoller 3 lesions associated with a cyst, an arthroscopic procedure for a meniscal suture or a resection of the distal leaf, depending on the complex nature or not of the lesion and the possibility of a suture, is indicated with a resection of the cyst by a direct approach.

\section{Conclusion}

The results of this series are good, comparable with the data in the literature, confirming the working hypothesis. They confirm the efficacy of a direct approach suture with cyst resection on these non-transfixing lesions, without added morbidity and with a good functional recovery.

Participation NG, HF, DE, ME: patient review, writing, and bibliography

FB, MO: proofreading and corrections

\section{Compliance with ethical standards}

\section{Conflict of interest NG, HF, DE: none}

MO: education consultant Arthrex, Stryker, and Newclip

ME: education consultant for Lepine, Newclip, and Amplitude and associate editor of the SOFCOT teaching conferences

FB: education consultant for Amplitude and Serf

Ethical approval All procedures performed in studies involving human participants were in accordance with the ethical standards of the institutional and/or national research committee and with the 1964 Helsinki declaration and its later amendments or comparable ethical standards. 


\section{References}

1. Campbell SE, Sanders TG, Morrison WB (2001) MR imaging of meniscal cysts: incidence, location, and clinical significance. AJR Am J Roentgenol 177:409-413

2. Romanini L, Calvisi V, Collodel M, Masciocchi C (1988) Cystic degeneration of the lateral meniscus. Pathogenesis and diagnostic approach. Ital J Orthop Traumatol 14:493-500

3. Stoller DW, Martin C, Crues JV 3rd., Kaplan L, Mink JH (1987) Meniscal tears: pathologic correlation with MR imaging. Radiology 163:731-735

4. Chen W, Zhao J, Wen Y et al (2015) Accuracy of 3-T MRI using susceptibility-weighted imaging to detect meniscal tears of the knee. Knee Surg Sports Traumatol Arthrosc 23:198-204

5. Beaufils P, Becker R, Verdonk R, Aagaard H, Karlsson J (2015) Focusing on results after meniscus surgery. Knee Surg Sports Traumatol Arthrosc 23:3-7

6. Meserve BB, Cleland JA, Boucher TR (2008) A meta-analysis examining clinical test utilities for assessing meniscal injury. Clin Rehabil 22:143-161

7. Sommerlath KG (1991) Results of meniscal repair and partial meniscectomy in stable knees. Int Orthop 15:347-350

8. Tegner Y, Lysholm J (1985) Rating systems in the evaluation of knee ligament injuries. Clin Orthop Relat Res 198:43-49

9. Beaufils P, Hardy P, Chambat P et al (2006) Adult lateral meniscus. Rev Chir Orthop 92(5 Suppl):2S169-2S194

10. Yulish BS, Montanez J, Goodfellow DB et al (1987) Chondromalacia patella : assessment with MR imaging. Radiology 164:763-766

11. Hulet C, Souquet D, Alexandre P, Locker B, Beguin J, Vielpeau C (2004) Arthroscopic treatment of 105 lateral meniscal cysts with 5year average follow-up. Arthroscopy 20:831-836

12. Bombaci H, Kuyumcu M, Coskun T, Kaya E (2016) When should the external approach be resorted to in the arthroscopic treatment of perimeniscal cyst ? SICOT J 20:19

13. Dai PY, Tan HL, Yuan YH, Li XY (2018) Arthroscopic cyst removal and wire-guided suture for the treatment of lateral meniscal cyst of knee joint. Zhongguo Gu Shang 31:944-948

14. Chen D, Li Q, Sun Y, Qin J, Yao Y, Jiang Q (2017) Arthroscopic management for the unstable inferior leaf of the lateral meniscus anterior horn and associated cysts through a direct inframeniscal portal: a retrospective study. Biomed Res Int 2017:9264907

15. Reagan WD, McConkey JP, Loomer RL, Davidson RG (1989) Cysts of the lateral meniscus: arthroscopy versus arthroscopy plus open cystectomy. Arthroscopy 5:274-281

16. Glasgow MM, Allen PW, Blakeway C (1993) Arthroscopic treatment of cysts of the lateral meniscus. J Bone Joint Surg Br 75B: 299-302

17. Calvisi V, Preite R, Romanini L (1989) Cystic degeneration of the external meniscus. Part 2: arthroscopic meniscectomy. Ital J Orthop Traumatol 15:33-41

18. Kumar NS, Jakoi AM, Swanson CE, Tom JA (2014) Is formal decompression necessary for parameniscal cysts associated with meniscal tear? Knee 21:501-503

19. Sarimo J, Rainio P, Rantanen J, Orava S (2002) Comparison of two procedures for meniscal cysts. A report of 35 patients with a mean follow-up of 33 months. Am J Sports Med 30:704-707

20. Beaufils P, Pujol N (2018) Meniscal repair: technique. Orthop Traumatol Surg Res 104:S137-S145

21. Pujol N, Bohu Y, Boisrenoult P, Macdes A, Beaufils P (2013) Clinical outcomes of open meniscal repair of horizontal meniscal tears in young patients. Knee Surg Sports Traumatol Arthrosc 21: $1530-1533$

22. Biedert RM (2000) Treatment of intrasubstance meniscal lesions : a randomized prospective study of four different methods. Knee Surg Sports Traumatol Arthrosc 8:104-108

23. Pujol N, Tardy N, Boisrenoult P, Beaufils P (2015) Long-term outcomes of all-inside meniscal repair. Knee Surg Sports Traumatol Arthrosc 23:219-224

24. Lozano J, Ma CB, Cannon WD (2007) All-inside meniscus repair: a systematic review. Clin Orthop Relat Res 455:134-141

25. Nepple JJ, Dunn WR, Wright RW (2012) Meniscal repair outcomes at greater than five years: a systematic literature review and metaanalysis. J Bone Joint Surg Am 94A:2222-2227

26. Cassard X, Verdonk R, Almqvist KF et al (2004) Meniscal repair. Rev Chir Orthop Reparatrice Appar Mot 90(8 Suppl):3S49-3S75 